\title{
Língua, semântica e história: a construção de sentidos sobre o delinquente
}

\author{
Langue, Sémantique et Histoire: La construction de sens sur le délinquant
}

\author{
Débora Massmann ${ }^{1}$ \\ Universidade Federal de Alagoas
}

\begin{abstract}
- RESUMO: A partir da perspectiva da Semântica Histórica da Enunciação ou Semântica do Acontecimento (Guimarães, 2002), este estudo se propõe a analisar a rede de significação que, historicamente, foi sendo produzida em torno da palavra "delinquente" na obra fundadora da criminologia científica. Interessa-nos analisar a reescrituração, um procedimento enunciativo que permite observar o modo como os sentidos vão se movimentando no acontecimento de dizer, colocando em funcionamento a memória, a história e o político.

- PALAVRAS-CHAVE: Língua. Semântica. História. Enunciação.

- ABSTRACT: Inscrit dans le domaine de la sémantique historique de l'énonciation ou sémantique de l'événement (Guimarães, 2002), cette étude se propose d'analyser le réseau de signification qui, historiquement, a été produite autour du mot "délinquant" dans l'œuvre fondatrice de la criminologie scientifique. Il nous intéresse d'analyser la réécrituration, une procédure énonciative qui permet d'observer la façon dont les sens se déplacent dans l'événement de dire en mettant en fonctionnement la mémoire, l'histoire et le politique.

- MOTS-CLÉS: Langue. Sémantique. Histoire. Enonciation.
\end{abstract}

O universo da significação, que faz dos textos o que são, é o que produz o envolvimento que nos transporta, que nos transforma, mesmo que este universo, na tranquilidade do cotidiano, pareça não fazer parte de nossas vidas, e que descobrimos que faz. (Eduardo Guimarães, 2011)

\section{Considerações iniciais}

As relações entre língua, semântica e história permitem compreender o processo de produção e de circulação de sentidos. Processo este que, para nós semanticistas, é político. Como nos ensina Guimarães, (2002, p. 12), enunciativamente, o político "é a contradição que instala o conflito no centro do dizer".

Inscritos nessa perspectiva de estudo dos fenômenos da linguagem, neste estudo, buscamos compreender a rede de significações que se produziu em torno da palavra "delinquente". O ponto de partida de nossa reflexão é a noção de criminologia. Cientificamente, segundo Renneville ${ }^{2}$ (2005, p. 3), parece haver um acordo que

\footnotetext{
${ }^{1}$ Doutora em Letras pela USP. Docente Permanente do Programa de Pós-Graduação em Linguística e Literatura da Universidade Federal de Alagoas. Maceió, Alagoas, Brasil. Email: massmann.debora@gmail.com

2 RENNEVILLE, M. Les Archives d'anthropologie criminelle: une revue pour une Science. In Criminocorpus [En ligne], Histoire de la criminologie. Paris: Jan. 2005. Acesso: 11 mai 2018. URL: http://journals.openedition.org/criminocorpus/104.
} 
considera a criminologia como "um discurso de pretensão científica visando o estudo e a compreensão do crime e do criminoso". De fato, muitos autores, em diferentes áreas do conhecimento ${ }^{3}$ e em diferentes épocas, têm se dedicado a compreender questões que concernem à criminologia. Apesar das diversas frentes de trabalho sobre o tema, a maioria dos estudiosos compreende e concorda que a noção de criminologia foi formulada na segunda metade do século XIX, sobretudo, a partir das pesquisas desenvolvidas por autores da escola positivista italiana, a saber, Lombroso, Ferri e Garofalo.

À época, esses autores produziram um movimento importante em torno da questão. Movimento este que se sustentou, num primeiro momento, na materialidade linguística: no que concerne ao objeto de estudo, especificamente, eles produziram um deslizamento terminológico do substantivo "crime", para o adjetivo "criminal"; e, num segundo momento, eles propuseram um deslizamento metodológico: o raciocínio legal deu espaço à experimentação científica (RENNEVILLE, 2005). Essas ações produziram efeitos de legitimação para a proposta que começava a circular em países como Itália, Alemanha, Espanha, Inglaterra, Estados Unidos e, mais adiante, no Brasil. Soma-se a esses gestos o fato de que, no final do século XIX, viveu-se um momento "científico" em efervescência, devido à multiplicação de congressos científicos, criação de revistas temáticas e abertura ao público de museus de criminologia. Como destaca Renneville ${ }^{4}$, "em 1885, é realizado em Roma o primeiro Congresso Internacional de Antropologia Criminal que tratou justamente do "Delinquente nato". Nesta ocasião, Lombroso e Garofalo dão a conhecer mais detalhes sobre sua proposta de estudo da Criminologia" (RENNEVILLE, 2005, p. 4) .

É, pois, neste contexto "científico" que o médico italiano Cesare Lombroso (1835-1909) se inscreveu como o fundador da criminologia "científica". De acordo com Kaluszynsky ${ }^{6}$, é preciso ter cautela com o sentido de cientificidade que é produzido aí. A proposta de Lombroso e de sua equipe pode ser considerada "científica de acordo com os critérios propostos naquela época e que residem no fato de que essa disciplina se funda na observação, se alimenta na interpretação dos fatos e na verificação dessa interpretação graças a uma experimentação aguda e estruturada" (KALUSZYNSKY, 2005, p. 1).

De fato, a teoria da criminologia de Lombroso foi formulada com base em resultados alcançados a partir da observação de mais de quatrocentas autópsias e mais de seis mil análises de pessoas vivas. Para Lombroso, era possível identificar o criminoso a partir de um conjunto de características físicas, fisiológicas, psicológicas e sociais. Assim, o delinquente teria os seguintes traços:

protuberância occipital, órbitas grandes, testa fugidia, arcos superciliares excessivos, zígomas salientes, prognatismo inferior, nariz torcido, lábios grossos, arcada dentária defeituosa, braços excessivamente longos, mãos grandes, anomalias dos órgãos sexuais, orelhas grandes e separadas, polidactia, etc.. As características anímicas, segundo o autor, são: insensibilidade à dor, tendência a tatuagem, cinismo, vaidade, crueldade, falta

\footnotetext{
${ }^{3}$ Por exemplo, na psicologia, Georget, Prosper Lucas, Paolo Zacchias, Esquirol, etc.; na sociologia, Tarde, Durkheim, Guerry, Lacassagne, etc.; na antropologia, Broca, Gall, Lombroso, etc.

${ }^{4}$ Pesquisador francês, especialista em história da ciência do crime e do criminal dos séculos XIX e XX.

${ }^{5}$ Reneville $(2005$, p. 3 ) destaca ainda que esse movimento, iniciado na Itália, rapidamente tem a adesão da França que em 1986 lança uma importante revista para área "Os arquivos de antropologia criminal" dirigidos por Lacassagne.

${ }^{6}$ In KALUSZYNSKI, M. « Quand est née la criminologie ? ou la criminologie avant les Archives... », In Criminocorpus [En ligne], Histoire de la criminologie, 2. Thématiques et théories, mis en ligne le 01 janvier 2005. Acesso em 11 mai 2018. URL : < http://journals.openedition.org/criminocorpus/126>.
} 
de senso moral, preguiça excessiva, caráter impulsivo (ALBERGARIA, 199, p.131).

É com base nesse método que em 1939 foi proposto, no Brasil, o Serviço de Biotipologia Criminal da Penitenciária do Estado de São Paulo. O serviço passou a funcionar efetivamente no ano seguinte (1940), no governo de Adhemar de Barros, interventor federal do Estado Novo, período em que o país vivia a ditadura Vargas. A função do Serviço de Biotipologia Criminal aqui no Brasil era fazer a medição dos detentos brasileiros e categorizar seus traços, conforme as especificações de criminalidade propostas por Lombroso: as características físicas comuns aos sujeitos serviriam para classificar os tipos de delinquência em $\mathrm{X}$ ou $\mathrm{Y}$ e contribuiriam para determinar a penalização. Segundo essa perspectiva, haveria, pois um pré-construído físico-biológico da delinquência.

\section{Dos sentidos}

Ainda que as ideias de Lombroso tenham sido rechaçadas, no século $\mathrm{XX}$, por correntes do Direito Penal e da Filosofia, fato é que sua obra produziu deslocamentos e marcou um grande período da história da nossa sociedade. É certo dizer que há uma memória de sentidos em torno de "delinquente" que, na e pela temporalidade do acontecimento de linguagem, produziu e produz efeitos nas enunciações que circulam em nossa sociedade. Assim, interessa-nos aqui refletir sobre o funcionamento da língua na sua relação com a sociedade: trata-se de analisar o processo de produção de sentidos que se produz em torno de "delinquente" em "O Homem delinquente" obra de Cesare Lombroso, publicada em $1876^{7}$. O objetivo é compreender a rede de sentidos que foi posta em funcionamento no conjunto de enunciações em que essa palavra apareceu e, sobretudo, observar os efeitos de sentido que vão se produzindo enunciativamente na história para "delinquente". Para isso, inscrevo-me no domínio da Semântica Histórica da Enunciação (Semântica do Acontecimento), tal como proposta por Guimarães (2002).

Inscrever-se neste domínio dos estudos em ciências da linguagem significa tratar dos fenômenos relativos à significação de uma maneira muito particular. Isso porque a semântica que fazemos, de um lado, sustenta-se numa posição estruturalista em trabalhos como aqueles desenvolvidos por Benveniste e Ducrot em que a língua tem um papel fundamental; por outro lado, essa perspectiva semântica dialoga fortemente com os estudos discursivos de cunho materialista, como aqueles propostos por Pêcheux e Orlandi, e traz para o centro dos debates sobre a significação, a história (SANTOS, 2013). História e língua constituem noções fundamentais para se compreender o processo de produção de sentidos na perspectiva em que nos situamos já que, para nós, a língua funciona na história. Vale dizer que a língua não está imune aos sentidos que foram produzidos na história de enunciações. É o funcionamento da língua no acontecimento enunciativo que materializa a memória de sentidos que foi se construindo na e pela história.

Desse modo, para analisar a enunciação é preciso levar em consideração três elementos, como nos ensina Guimarães: a exterioridade (história), a memória do dizer e a língua. Ao tratar da análise da enunciação, o autor explica que não se trata de compreender "como uma situação modifica sentidos da língua, mas como o exterior da enunciação constitui sentidos no acontecimento, ou melhor, como a memória interdiscursiva e a língua significam no presente do processo incessante da história dos

\footnotetext{
${ }^{7}$ Neste estudo, estamos trabalhando com a quarta edição desta obra que foi publicada em 1887.
} 
sentidos" (GUIMARÃES, s/d, p. 3) ${ }^{8}$. Ao dizer isso, Guimarães coloca o acontecimento enunciativo como um objeto muito particular para a análise semântica uma vez que o acontecimento é inquestionavelmente partícipe da significação.

Considerando o dispositivo teórico-analítico da Semântica Histórica da Enunciação (Semântica do Acontecimento), o enunciado se apresenta como uma unidade de análise absolutamente produtiva para os objetivos deste estudo. Isso porque ele permite observar o funcionamento de sentidos da palavra "delinquente" nas relações que ela estabelece com outras palavras no interior do próprio enunciado e, também, entre os diferentes enunciados que compõem o texto "O Homem delinquente". Em ambos, trata-se sempre de tomar a palavra e a rede de significação que se produz em torno dela, a partir de uma perspectiva relacional, isto é, analisar "delinquente" nas relações de determinação semântica que se produzem no acontecimento enunciativo.

É importante lembrar que, no acontecimento enunciativo, pelo funcionamento político e histórico, os sentidos da palavra "delinquente" se movimentam, deslizam transmutando sua significação. Para nós, a significação em si não está previamente dada, cristalizada, pronta e encapsulada. Mas é constituída de uma memória que historicamente foi sendo produzida. Em cada acontecimento, a significação é atualizada (funcionamento da temporalidade) e ela se (re)constrói, se reconfigura semanticamente a partir de relações que vão se estabelecendo no fio do dizer. É preciso então atentar para as condições sócio-históricas e ideológicas que sustentam e afetam $o$ acontecimento enunciativo: de fato, observando o funcionamento da língua em dizeres específicos sobre "delinquente", na obra de Lombroso, compreendemos a significação que ali é produzida e que se materializa sob a forma de outras/novas enunciações. Estas, por sua vez, reescrevem, retomam e re-significam dizeres sobre "delinquente" que circularam ou circulam em nossa sociedade.

Para observarmos os movimentos semânticos de "delinquente", trabalhamos com a reescrituração como procedimento enunciativo fundamental à análise. Trata-se, justamente, de descrever, interpretar e compreender o percurso da significação na textualidade da obra de Lombroso. Afinal, que sentidos são produzidos para "delinquente"? Como esses sentidos se movimentam nos dizeres deste autor? Que efeitos esses sentidos produzem/produziram na história?

No acontecimento enunciativo, a reescrituração, como sabemos, faz mover a significação de uma palavra desestabilizando já-ditos e alterando fronteiras semânticas. Para nós, a reescrituração traz consigo um poder constitutivo de ruptura, de (re)divisão e, consequentemente, (re)significação. Tem-se assim que a reescrituração é política. Nesse sentido, ela pode ser revolucionária, ou seja, fazer a significação romper, furar e irradiar para outros sentidos. Rancière, filósofo francês, explica que as palavras "embaralham a evidência segundo a qual as coisas seriam simplesmente o que elas são" $\left(\right.$ RANCIÈRE, $2005^{9}$ ). De nossa parte, podemos dizer que a reescrituração, ao ser posta em funcionamento, pode embaralhar, misturar os sentidos. Trata-se do movimento de ir e vir da significação que se produz no acontecimento de linguagem numa perpétua relação com a língua e com a história. Nesse movimento incessante da história das enunciações, o sentido se rompe e conduz à efervescência de outros/novos sentidos. Isso quer dizer que, como nos ensina Rancière, não há palavras revolucionárias por si só

\footnotetext{
${ }^{8}$ In Série Escritos. Disponível em <http://www.labeurb.unicamp. br/portal/pages/pdf/escritos/Escritos2.pdf > Acesso em 10 jun. 2016.

9 In Ciência e Cultura. Disponível em http://cienciaecultura.bvs.br/scielo.php?script=sci arttext\&pid=S000967252005000400011. Cienc. Cult. vol.57 no.4 São Paulo Oct./Dec. 2005. Acesso em 15 jun. 2017.
} 
(RANCIÈRE, $2005^{10}$ ). As palavras se tornam revolucionárias porque os sujeitos, no acontecimento de dizer que se produz em determinadas condições históricas, políticas, sociais e ideológicas, vão alterando o funcionamento das palavras, produzindo, nessa relação da linguagem com a sociedade, novas significações. Dito de outro modo, as palavras vão sendo ressignificadas à medida que elas são reescritas e assim, pelo funcionamento político e histórico, no fio do dizer, rompem-se e modificam-se. Tornam-se, portanto, palavras revolucionárias. Ou ainda, palavras políticas.

O processo de reescrituração, como destaca Guimarães, não se dá apenas ao longo de um único texto. Ele pode acontecer na relação entre diferentes textos produzidos em época distintas. Isso porque "a língua significa no presente do processo incessante da história dos sentidos" (GUIMARÃES, s/d, p. 3) ${ }^{11}$. Com efeito, a língua, pela reescrituração no acontecimento de dizer, coloca em funcionamento a memória de sentidos de uma palavra: trata-se da relação constitutiva entre língua e história, de que já falamos acima, e sobretudo, do funcionamento político da linguagem. Disputa de sentidos. Contradição que se funda na relação língua e história e se materializa no dizer.

\section{Da análise}

Em "O homem delinquente", o interesse do médico Lombroso não está direcionado à patologia ou à delinquência propriamente dita. Considerada como o marco a Antropologia Criminal, sua obra se propõe a estabelecer padrões, características e perfis categorizando-os em função dos delitos cometidos, contribuindo assim para a penalização. Como já se destacou anteriormente, a perspectiva de Lombroso, à época, foi considerada inovadora pois deslocou o centro de interesse da delinquência (crime) em direção ao indivíduo que a pratica (homem delinquente), ao delinquente nato. Dito de outra forma, a contribuição de Lombroso para sua área, de um modo geral, reside justamente no fato de que ele alterou o olhar do sistema de penalização colocando o sujeito no centro dos debates. Ele procura mostrar que a delinquência resulta das ações do próprio indivíduo que pode ser um delinquente nato. E, a partir dessa ideia, de acordo com Kaluszynski (2005, p. 3), "emerge a necessidade de conhecer o indivíduo acusado, indiciado, julgado, culpado. Pouco a pouco, o delinquente aparece (em paralelo ao delito) sai da inexistência, da indiferença onde era mantido" 12 .

O funcionamento de sentidos em torno de "delinquente" começa a partir do título da obra: "O homem delinquente" (recorte 1). Ao estabelecer a paráfrase $(\mathrm{O}$ homem é delinquente), compreendemos, pela relação de predicação, que "o homem" determina "delinquente":

\section{o homem $\dashv$ DELINQUENTE}

Mas quem é esse "homem"? Observemos que a utilização do artigo definido "o" permite-nos pensar que não se trata de qualquer homem, mas daquele homem que é

\footnotetext{
10 In Ciência $\quad$ e $\quad$ Cultura. $\quad$ Disponível em http://cienciaecultura.bvs.br/scielo.php?script=sci arttext\&pid=S0009-67252005000400011. Cienc. Cult. vol.57 no.4 São Paulo Oct./Dec. 2005. Acesso em 15 jun. 2017.

11 In Série Escritos. Disponível em $<$ http://www.labeurb.unicamp.

br/portal/pages/pdf/escritos/Escritos2.pdf > . Acesso em 10 jun. 2016.

12 Nossa tradução.
} 
determinado de forma precisa "o homem delinquente". Avançando na análise do texto, deparamo-nos, com o recorte 2 :

Recorte 2: Graças a eles [autores citados por Lombroso no parágrafo anterior], pela primeira vez, pude distinguir com precisão o delinquente nato, não só do delinquente ocasional, mas ainda o louco e o alcoólatra, para quem eu propus monografias especiais ${ }^{13}$ (LOMBROSO, 1887, p. 21).

Observemos que o processo de reescrituração que se inicia já põe em funcionamento possíveis respostas para a pergunta que fizemos acima, a saber, quem é o homem que é delinquente?. De fato, pelo funcionamento enunciativo, observamos que, no acontecimento de linguagem que se materializa no prefácio ${ }^{14}$ em estudo, "o homem delinquente" é reescrito por expansão sob a forma de especificações (enumerativas-aditivas-restritivas), como se observa em:

"pude distinguir com precisão o delinquente nato ${ }^{15}$, não só do delinquente ocasional, mas ainda o louco e o alcoólatra, para quem eu propus monografias especiais".

As especificações têm aqui um funcionamento muito interessante: ao detalhar quem pode ser considerado o homem delinquente, o sentido deste vai sendo delimitado. Esse funcionamento se dá, de acordo com Bréal, pela a "ação que as palavras exercem, à distância, umas sobre as outras. Uma palavra é levada a restringir cada vez mais sua significação, pelo fato de existir uma companheira que estende a sua" (BRÉAL, 2008, p. 182). De fato, trata-se de um processo de convivência semântica simbiótica, isto é, no curso do dizer, os sentidos das palavras vão se relacionando, se associando, se delimitando, se ampliando. Dito de outra maneira, eles vão se significando e se (re)significando a partir da relação língua e história. Podemos dizer, por exemplo, que, pelas relações de sentido que as palavras vão tecendo entre si, o sentido de "delinquente nato" é delimitado pelo sentido de "delinquente ocasional", assim como o sentido de "o louco" delimita o de "o alcoólatra".

É importante ainda observar, neste recorte, o uso da conjunção correlativa copulativa/aditiva "não só...., mas ainda...". Do modo como se apresenta, neste enunciado, ela tem um papel fundamental no processo de significação que sustentará a principal tese de Lombroso, a saber, aquela de que a delinquência é uma característica inata. Através do funcionamento de "não só..., mas ainda...", toma-se conhecimento de que existem, no mínimo, dois tipos que podem ser considerados delinquentes: o "delinquente nato" e o "delinquente ocasional" sendo que ambos se distinguem do "louco" e do "alcoólatra". Se por um lado, o uso da conjunção correlativa copulativa/aditiva "não só...., mas ainda..." coloca "delinquente" "ocasional", "louco" e "alcoólatra" em relação aditiva, por outro lado, ela coloca em funcionamento uma relação opositiva entre essas enumerações e delinquente nato de modo que "o louco" e "o alcoólatra" são colocados à margem uma vez que, de acordo com o autor, merecem um estudo específico: "para quem eu propus monografias especiais".

A partir do Recorte 2, as paráfrases produzidas permitem propor uma representação do funcionamento de sentidos no DSD 2, aqui abaixo:

R2' O homem é delinquente

\footnotetext{
${ }^{13}$ Grifos nossos.

${ }^{14}$ Edição da obra publicada em 1887.

${ }^{15}$ Grifos nossos.
} 
R2"' O delinquente é nato

$\mathrm{R} 2$ "' $\mathrm{O}$ delinquente é ocasional

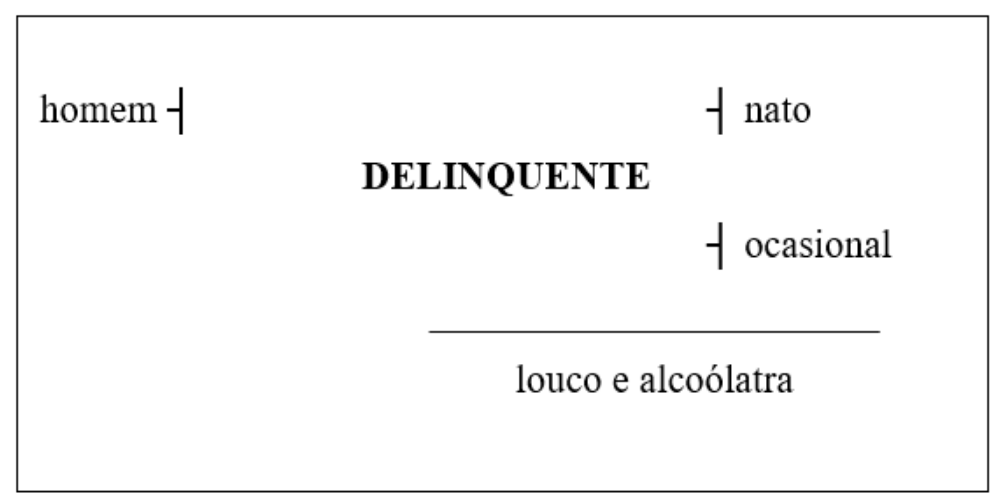

Observe que, neste DSD 2, "delinquente" é determinado por "homem" e determina "nato" e "ocasional". Além disso, o jogo semântico nos permite observar que "delinquente" está em uma relação de antonímia com "louco" e "alcoólatra".

Avançando no processo de análise, tomando a continuidade do prefácio como lugar de observação, no recorte 3 , é possível verificar que uma rede de significações vai se formando e, a partir dela, entrelaçam-se sentidos de e sobre o "delinquente", como podemos observar no recorte 3 :

Recorte 3: Graças a eles ${ }^{16}$ [autores citados por Lombroso no parágrafo anterior de seu prefácio], ainda, pude alargar minhas pesquisas nas formas primordiais da delinquência no selvagem, na criança e no animal, completando o estudo anatômico, começando o estudo fisiológico, especialmente sobre anomalias da sensibilidade, da reação vascular e do reflexo, fenômenos (...) que encontramos, tão frequentemente, nos indivíduos, apesar de inválidos desde seu nascimento, como são os delinquentes (LOMBROSO, 1887, p. 21).

Neste recorte, é possível verificar que uma rede de significações vai se formando e, a partir dela, entrelaçam-se sentidos em torno de delinquência e de "delinquente". A expressão "nas formas primordiais da delinquência no selvagem, na criança e no animal" põe em funcionamento sentidos de e sobre "delinquente": o delinquente é aquele que pratica a delinquência. Logo "selvagem", "criança" e "animal" à medida que estão articulados a "delinquência", neste recorte, reescrevem por expansão enumerativa "delinquente" uma vez que vão especificando formas "primordiais" de delinquência observadas por Lombroso em suas pesquisas anatômicas. Mais adiante, em "anomalias da sensibilidade, da reação vascular e do reflexo, fenômenos (...) que encontramos, tão

\footnotetext{
${ }^{16}$ Autores citados por Lombroso no parágrafo anterior de seu prefácio que reproduzimos aqui na integra: "MM. Liszt, Kraepelin, Biliakow, Troiski, Körnfeld, Knecht, Holtzendorf, Sommer, Kirchenheim, Mendel Pulido, Echeverria, Zanches, Drill, Kowalewski, Likaceff, Minzloff, Kolokoloff, Espinas, Letourneau, Tonnini, Reinach, Soury, Corre, Motet, Orchanski, Manouvrier, Fioretti, Le Bon, Bordier, Bonnet, Roussel, Ribot, Heger, Albrecht, Warnott, Lenhossek, Tamburini, Frigerio, Laschi, Mayor, Majno, Benelli, Fulci, Pavia, Aguglia, Sergi, Tanzi, Campili, Barzilai, Pugliese, Morello, Lessona C., Cosenza, Lestingi, Colucci, Turati, Marro, Venezian, et surtout grâce à MM. Lacassagne, Flesch, Benedikt, Beltrani-Scalia, Virgilio Morselli, Garofalo, Puglia et Ferri” (LOMBROSO, 1887, p. 21).
} 
frequentemente, nos indivíduos, apesar de inválidos desde seu nascimento, como são os delinquentes", observamos que "anomalias" determinam tanto os "indivíduos inválidos desde seu nascimento" e "delinquente". E estes, por sua vez, estão funcionando em relação de sinonímia. Essa trama semântica pode ser representada da seguinte maneira no DSD 3:

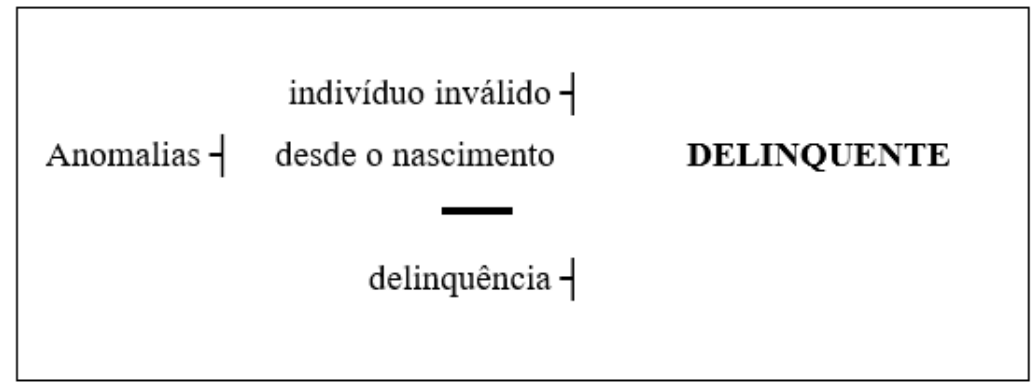

A partir desses enunciados analisados, podemos observar que Lombroso tece uma rede de sentidos para "delinquente" sustentado em uma memória que se inscreve no discurso da biologia. De fato, o autor recorre à teoria da evolução de Charles Darwin para explicar sua tese da delinquência nata, da delinquência como uma anomalia resultante do processo de "evolução" milenar que vai do homem primitivo ao homem contemporâneo (a Lombroso).

No prefácio, no sumário e ao longo do texto, a perspectiva anatopatológica e antropométrica do autor tem como ponto de referência o reino vegetal/animal. É a partir dessa análise que ele propõe critérios, que se sustentam em perfis de homens e mulheres, ditos "normais" (assim como era realizado na Biologia), para, a partir dali, estabelecer traços patológicos e anomalias do que ele vai chamar "delinquente nato".

Segundo Kaluzincky, em conformidade com essa teoria da evolução, Lombroso vai chamar a atenção para a semelhança do comportamento dos delinquentes relacionando-o ao comportamento dos animais selvagens, como vimos acima nas análises: "homem selvagem em seu físico e seu espírito, homem desnaturado e, ao mesmo tempo, muito próximo da Natureza, tal é, de acordo com este mestre da observação dos homens e de seus Crânios, o retrato do delinquente nato (KALUZINCKY, 2005, p. 5). Como destaca o autor, essa descrição do delinquente nato é complementada ainda pelo estudo social que compreende a religião dos delinquentes, sua inteligência, seu grau de instrução, suas gírias, sua escrita, sua literatura, sua arte, seu corpo, suas tatuagens e sua engenhosidade.

À medida que os sentidos de "delinquente" em Lombroso associam-se ao discurso da biologia, sobretudo, a este discurso evolucionista, observa-se o funcionamento do que se pode chamar de "poder da norma" (FOUCAULT, 1998). É através deste "poder da Norma" que as instituições (como o Estado, por exemplo) e os discursos (como o da ciência, por exemplo) estabelecem o 'normal' como coerção social. Trata-se do processo de normatização social, normalização, padronização. O que foge ao "normal" é desvio, doença, delinquência. O que foge ao "normal" precisa ser controlado. A força deste princípio regulador pode ser observada ainda na sociedade atual que não se desvencilhou desta memória histórico-ideológica que remete ao sentido disciplinar e regulador do corpo social/individual.

\section{O acontecimento temporaliza}


No início dessa reflexão, lançamos alguns questionamentos em torno dos sentidos de "delinquente", a saber, afinal, que sentidos são produzidos para "delinquente" em Lombroso? Como esses sentidos se movimentam nos dizeres deste autor? As respostas foram sendo apresentadas ao longo de nossas análises. Entretanto, resta ainda dizer que efeitos esses sentidos de "delinquente" produzem/produziram na história?

Ainda que as teses de Lombroso tenham sido refutadas por vários cientistas do Século XX, os sentidos que foram postos em funcionamento a partir de suas ideias não foram silenciados/apagados. Se observarmos o funcionamento da nossa sociedade, veremos que há um "resto" de memória que se mantém presente (preservada) e que se atualiza no perpétuo processo de triangulação entre língua, acontecimento e história Lombroso, ao reunir os aspectos biológicos aos aspectos sociais, criou um mecanismo de esteriotipização, de segregação e, podemos dizer, de exclusão: quem é o delinquente hoje? Que memória ou que sentidos se produz, por exemplo, em torno do sujeito do grafite, do pixo, do piercing, da tatuagem (ORLANDI, 2006), do rap, do funk, do negro, do morador de rua, do morador da favela, do mendigo, do traficante, do flanelinha, do terrorista, do refugiado, do presidiário, do criminoso, etc.? Todas as designações em torno destes sujeitos que estão/são, aparentemente, à margem da sociedade contemporânea colocam em funcionamento uma memória (interdiscurso) que se atualiza no acontecimento de dizer projetando novos/outros sentidos, mas sempre deixando um resíduo de significação que faz presente e (in)visível o sentido de "delinquente" de Lombroso. O sentido de "delinquente" que vai resultar sempre, como nos ensina Orlandi (2009), da divisão maniqueísta entre o Bem e o Mal.... o doente e o saudável.... o normal e o delinquente....

\section{REFERÊNCIAS}

ALBERGARIA, J. Noções de Criminologia. Belo Horizonte, Mandamentos, 1999.

BRÉAL, M. Ensaio de semântica. Campinas: Pontes, 2008.

FOUCAULT, M. Vigiar e punir. Trad. Raquel Ramalhete. 18.Ed. Petrópolis: Vozes, 1998.

GUIMARÃES, E. Semântica do Acontecimento. Campinas: Pontes, 2002.

Os Limites do Sentido. 2.ed. Campinas: Pontes, 1995.

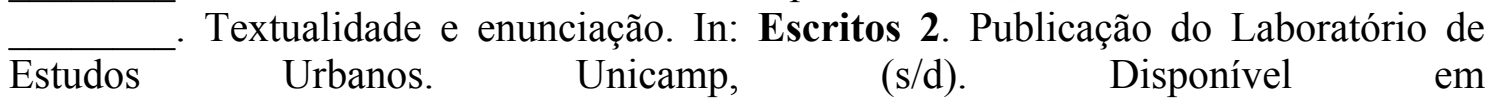
$<$ http://www.labeurb.unicamp.br/portal/pages/pdf/escritos/Escritos2.pdf $>$. Acesso em 08 jul. 2019.

Textualidade e enunciação. In Série Escritos. Disponível em

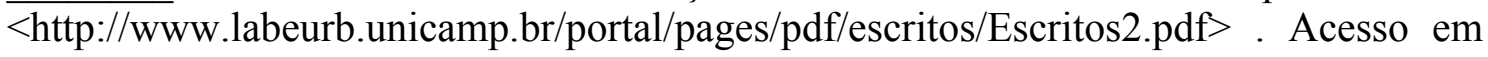
10 jun. 2019.

KALUSZYNSKI, M. "Quand est née la criminologie ? ou la criminologie avant les Archives", In Criminocorpus [En ligne], Histoire de la criminologie, 2. Thématiques et théories, mis en ligne le 01 janvier 2005. Acesso em 11 mai 2018. URL : $<$ http://journals.openedition.org/criminocorpus/126>.

LOMBROSO, C. L'homme criminel. Trad. MM. Régnier et Bournet. 4. Ed. Paris: Félix Alcan Éditeur, 1887. 
RENNEVILLE, M. Les Archives d'anthropologie criminelle: une revue pour une Science. In Criminocorpus [En ligne], Histoire de la criminologie. Paris: Jan. 2005. Acesso: 11 mai 2018. URL : <http://journals.openedition.org/criminocorpus/104>.

ORLANDI, E. P. Espaço da violência: o sentido da delinquência. In Cadernos de Estudos Linguísticos. Campinas, n51(2), Jul./Dez. 2009. p. 219-234 . À flor da pele: indivíduo e sociedade. In: MARIANI, B. A escrita e os escritos: reflexões em análise de discurso e psicanálise. São Carlos: Claraluz, 2006. RANCIÈRE, J. Entrevista com Jacques Rancière. In Ciência e Cultura. Disponível em $<$ http://cienciaecultura.bvs.br/scielo.php?script $=$ sci arttext\&pid $=$ S0009-

67252005000400011>. Cienc. Cult. vol.57 no.4 São Paulo Oct./Dec. 2005. Acesso em 15 jun. 2019.

SANTOS, G. L. Enunciação, designação e metáfora: um estudo sobre o político na linguagem. In Entremeios. n.6 Jan, 2013. Disponível em $<\underline{\text { http://www.entremeios.inf.br/index.php?issue }=6}>$. Acesso em 08 jul. 2019.

Recebido em: novembro de 2019.

Aprovado em: dezembro de 2019.

\section{Como citar este trabalho:}

MASSMANN, D. Língua, semântica e história: a construção de sentidos sobre o delinquente. Traços de Linguagem. V.3, n.2, p. 42-51, 2019. 